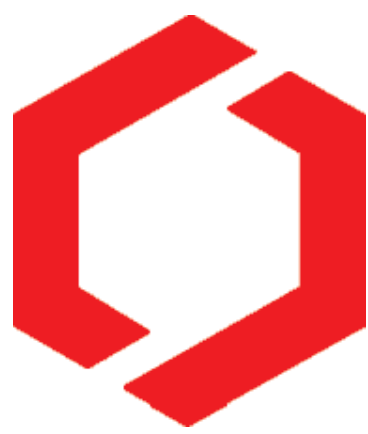

SCHWEIZ. CHEMISCHE GESELLSCHAFT SOCIETE SUISSE DE CHIMIE SWISS CHEMICAL SOCIETY

DIVISIONS :

ANALYTICAL CHEMISTRY

MEDICINAL CHEMISTRY

CHEMICAL RESEARCH

POLYMERS \& COLLOIDS
DIVISIONEN :

ANALYTISCHE CHEMIE

MEDIZINISCHE CHEMIE

CHEMISCHE FORSCHUNG

POLYMERE UND KOLLOIDE
DIVISIONS :

CHIMIE ANALYTIQUE

CHIMIE MÉDICINALE

RECHERCHE CHIMIQUE

POLYMĖRES ET COLLOÏDES

\title{
Fall Meeting 2008 Herbstversammlung 2008 Assemblée d'automne 2008
}

Thursday, September 11th, 2008

Donnerstag, 11. September 2008 Jeudi, 11 septembre 2008

\section{Zürich}




\section{Organizing Committee}

Prof. Heinz Berke - University of Zurich (Chairman)

Prof. Claude Daul - University of Fribourg

Prof. Peter Hamm - University of Zurich

Prof. Frederic Merkt - ETH Zürich (Chairman)

Prof. Martin Quack - ETH Zürich

Prof. Jay Siegel - University of Zurich

Prof. Jürg Hutter - University of Zurich

Prof. Jacques Moser - EPF Lausanne
Dr. Ferdinand Wild - University of Zurich

Prof. Nathaniel Finney - University of Zurich

Dr. Hans Peter Märki - F. Hoffmann-La Roche Ltd

Prof. Paul S. Pregosin - ETH Zürich

Prof. Kay Severin - EPF Lausanne

Prof. Thomas Ward - University of Neuchâtel

Prof. Renato Zenobi - ETH Zürich

Prof. A. Dieter Schlüter - ETH Zürich

Prof. Stefan Seeger - University of Zurich

\section{Secretariat}

Mrs. Bea Spichtig

Anorganisch-chemisches Institut der Universität Zürich

Winterthurerstrasse 190

CH-8057 Zürich

Tel.: +41 44635 4646, E-Mail: spichtig@ aci.uzh.ch

\section{SCS Mettler-Toledo Awards}

The awards for the best oral presentations at the SCS Fall Meeting 2008 are sponsored by METTLER TOLEDO AG, CH-8660 Greifensee. The organizers wish to thank Thomas Nitschke, METTLER TOLEDO, for presenting the awards.

\section{Career Center}

In collaboration with the SCS Jungchemikerforum, a career center will be established during the Fall Meeting. The Human Resources Departments of several renowned chemical companies will be present.

\section{Jungchemikerforum}

Young chemists can meet up in the Jungchemikerforum, the 'Nachwuchs' organisation within the Division of Chemical Research of SCS. Interested participants are invited to join. There will be an information desk.

\section{Information}

Admission: Admission to the Fall-Meeting is open to everyone. However, while SCS members have free access, non-members will be charged a conference fee of CHF 50.-. SCS members must identify themselves - please bring your SCS membership card 2008 with you!

Registration: Registration for the SCS Fall Meeting is only required for those presenting a scientific contribution. The Swiss Chemical Society bears the printing costs of CHF 200.- per abstract for their members. Therefore the publication of the scientific contribution (abstract) in CHIMIA is free if the presenting author (the author whose name is underlined in the abstract) is a member of the Swiss Chemical Society. Non-members will charged CHF 200.- to cover the printing expenses.

To register as a new SCS member please visit http://www.scg.ch/org/member.html

Lunch: Drinks, coffee and snacks will be offered by the SCS in the vicinity of the poster session. A cafeteria and a restaurant are located next to the meeting venues.

Coffee breaks: Coffee and drinks will be available until 11.00 in the morning and a coffee break will be organized between 17.00 and 17.30, before the Paracelsus Prize presentation. 


\section{Transportation}

Although the University of Zurich-Irchel does have a large car park, travel by train is recommended. From the main station, the University Zurich-Irchel can be reached by tram no. 10 (leave at tramstop Irchel, 15 min) or by trams 7 or 14 (leave at tramstop Milchbuck, $10 \mathrm{~min}$ ). From both stops a five minute walk takes you to the campus.

\begin{tabular}{|l|c|c|c|c|c|l|}
\hline \multicolumn{9}{|c|}{ Morning } & \multicolumn{3}{c|}{ Evening } \\
\hline Train from & Departure & Arrival & & Departure & Arrival & Train to \\
\hline Basel & 07.07 & 08.00 & Zürich & 19.34 & 20.38 & Basel \\
& 07.14 & 08.24 & & 20.02 & 20.56 & \\
\hline Bern & 07.02 & 07.58 & Zürich & 19.32 & 20.56 & Bern \\
& 07.32 & 08.28 & & 20.00 & 20.57 & \\
\hline Fribourg & 06.34 & 07.58 & Zürich & 19.32 & 20.54 & Fribourg \\
& 08.04 & 09.28 & & 20.00 & 21.25 & \\
\hline Genève & 04.56 & 07.56 & Zürich & 19.32 & 22.15 & Genève \\
& 05.36 & 08.28 & & 20.04 & 23.04 & \\
\hline Lausanne & 05.45 & 07.58 & Zürich & 19.32 & 21.40 & Lausanne \\
& 06.20 & 08.28 & & 20.04 & 22.15 & \\
\hline Neuchâtel & 06.24 & 07.56 & Zürich & 19.32 & 21.21 & Neuchâtel \\
& 06.43 & 08.28 & & 20.04 & 21.32 & \\
\hline
\end{tabular}

\section{Irchel Campus}

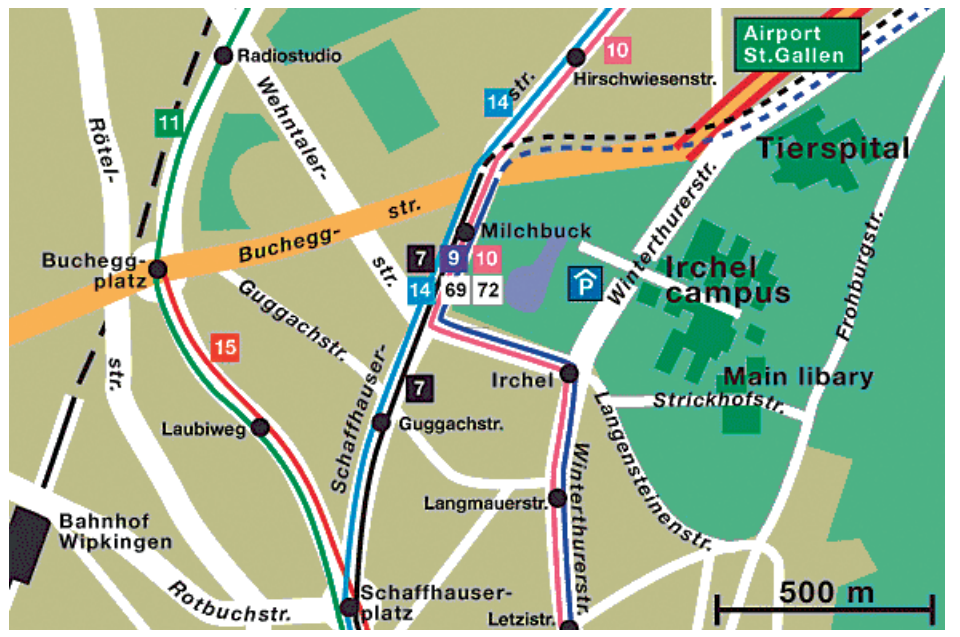

The meeting will be held in the 'Lichthof' area and in the surrounding auditoria.

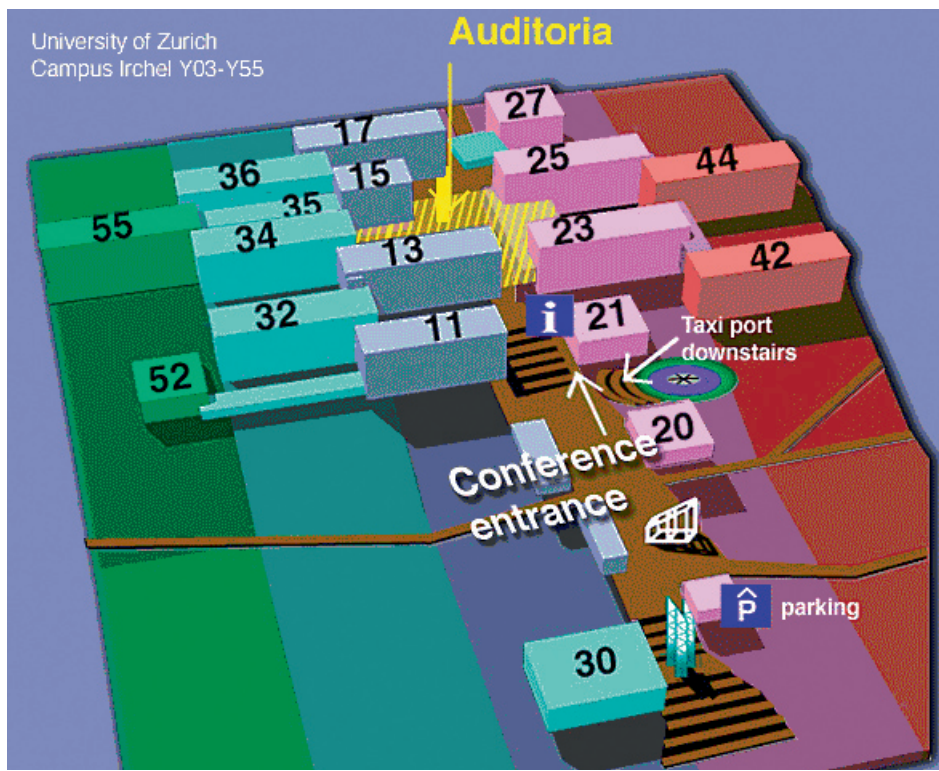




\section{Detailed Map of Lecture Rooms}

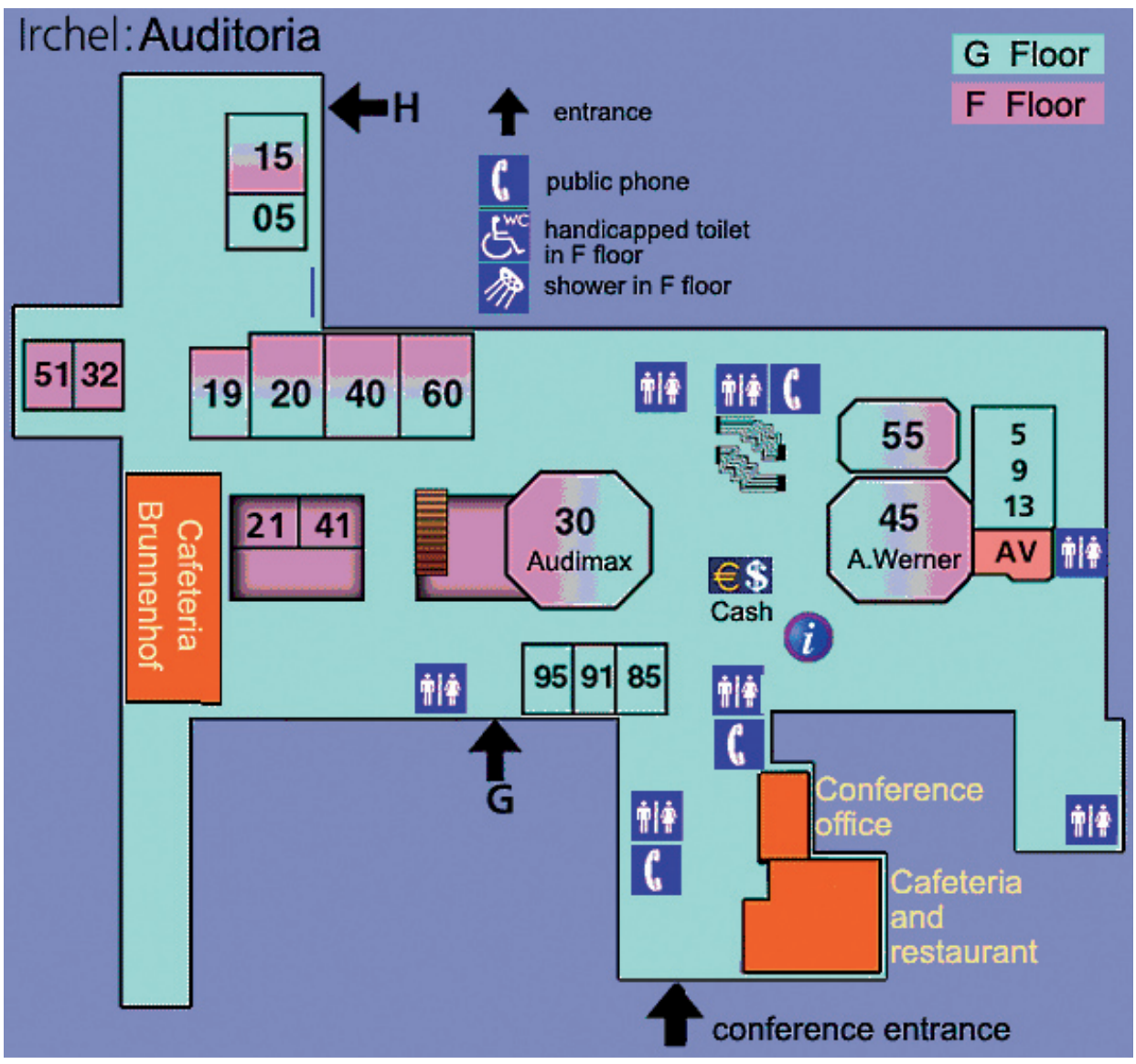

HS 30: Opening Ceremony,

Plenary Lectures and

Inorganic and Coordination

Chemistry

HS 45: Organic Chemistry I

HS 60: Organic Chemistry II

HS 40: Physical Chemistry

HS 95: Analytical Chemistry

HS 91: Medicinal Chemistry

HS 85: Computational Chemistry

HS 55: Polymers and Colloids

HS 20: Meeting of the Photochemistry Group

\section{Sponsors}

The organization of the meeting gratefully acknowledges the generous support of the following fine companies (see the meeting website http://scs-fallmeeting.uzh.ch for an updated list of sponsors):

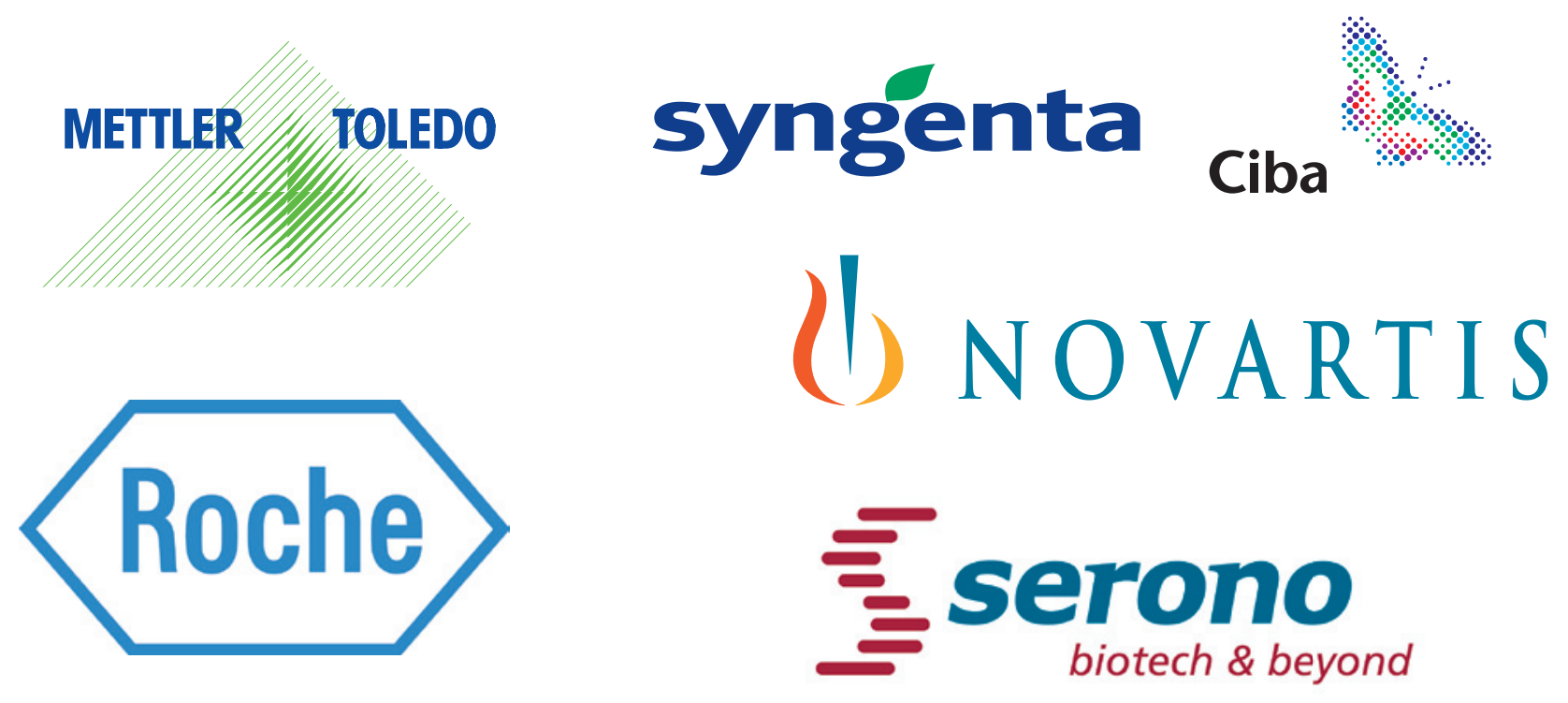




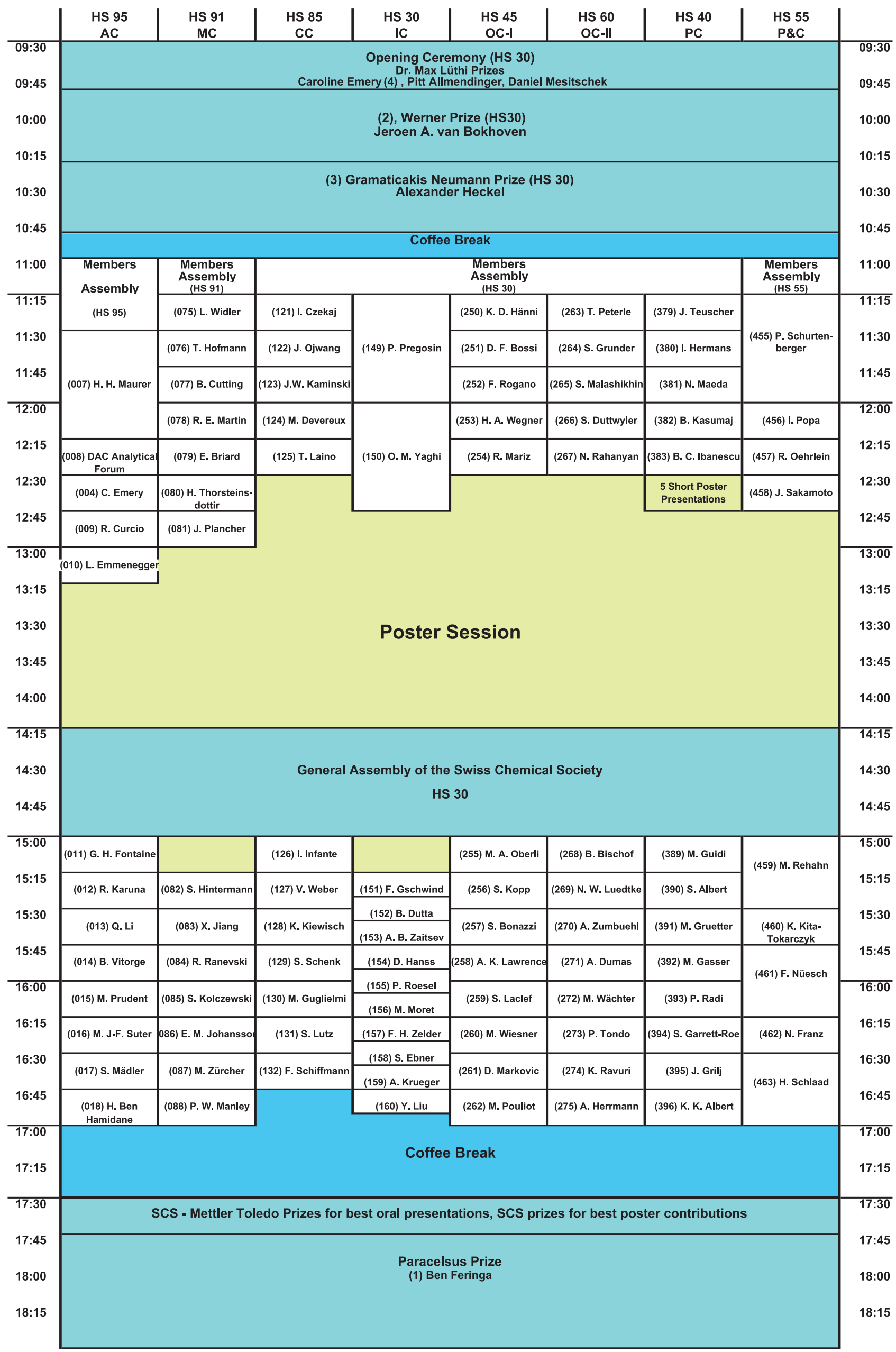

